\section{AB1461-HPR FREQUENCY OF RHEUMATOID FACTOR ISOTYPES IN PARAGUAYAN PATIENTS WITH RHEUMATOID ARTHRITIS}

$\underline{\text { L Roman }}^{1}$, S. Riquelme-Granada ${ }^{1}$, G. Avila-Pedreti ${ }^{1}$, I. Acosta-Colman ${ }^{1}$, M. E. Acosta ${ }^{2}$, I. de Guillen ${ }^{2}$, M. Duarte ${ }^{1}$, M.T. Filartiga ${ }^{3}$, S. Cabrera-Villalba'.

${ }^{1}$ Reumatologia, Hospital de Clinicas; ${ }^{2}$ Investigación, Instituto de Investigación de Ciencias de la Salud, San Lorenzo; ${ }^{3}$ Laboratorio, Laboratorio Curie, Asunción, Paraguay

Background: Rheumatoid Arthritis is a chronic rheumatic disease characterised by polyarticular inflammation. The rheumatoid factor is one of the most known prognostic markers, not only its presence, but also the levels. It also presents different isotypes (IgG, $\lg M$, IgA), which can affect the course of the disease.

Objectives: To analyse the presence of different rheumatoid factor (RF) isotypes in Paraguayan patients with rheumatoid arthritis (RA) and to study their association with clinical and analytical characteristics.

Methods: Descriptive, cross-sectional study. A large number of clinical and serological variables were recorded. The anti-CCP 3.1 and Rheumatoid factor (RF) isotypes IgA, IgG, and IgM were measured in serum samples by ELISA (enzyme-linked immunosorbent assay) $(\mathrm{NV}<17 \mathrm{U} / \mathrm{ml})$. Statistical analysis was performed using SPSS v.23. Quantitative variables were characterised by their means and standard deviations, while the qualitative variables were characterised according to the percentage of patients. The comparison of clinical and serological variables was performed using the chi-squared test and the student test respectively for qualitative and quantitative variables.

Results: 103 patients with RA were included, $86.4 \%$ were female, with a median age of onset of $44.7 \pm 13.6$ years, and the mean disease duration was $7.13 \pm 7.03$ years. The olygoarticular onset was the most frequent (46.6\%). $13.7 \%$ were smokers. Extra-articular manifestations were present in $13.5 \%$. The most frequent treatment was methotrexate (84.3\%). Erosions were observed in $43.2 \%$ of patients. $28 \%$ were in remission of the disease measured by the DAS28 index. The average of HAQ was $0.47 \%$ \pm 0.58 . $91.3 \%$ had anti-CCP positive, the mean anti-CCP levels were $290.5 \pm 152.8 \mathrm{U} / \mathrm{mL}$. RF isotypes was observed in $75.7 \%, 53.4 \%$ and $38.8 \%$ for $\operatorname{lgM}$, IgA and $\lg$ respectively. Mean levels were as follow, IgA $85.62 \pm 56.6 \mathrm{U} / \mathrm{mL}$, IgM $96.7 \pm 30.9 \mathrm{U} / \mathrm{mL}, \operatorname{lgG} 70.98 \pm 72.42 \mathrm{U} / \mathrm{mL}$. $32 \%$ of the patients had 2 isotypes of RF, while $25.2 \%$ had the 3 isotypes. The $57.3 \%$ had $\geq 2$ isotypes of RF. We did not find significant differences when comparing gender, age, disease duration, form of onset, extraarticular manifestations, smoking status, erosions, disease activity, HAQ, treatment, between the different RF isotypes, and levels, except in the presence of anti-CCP with the RF-IgM isotype $(p<0.000)$.

Conclusions: This is the first study of RF isotypes in Paraguayan patients with RA. The most frequent isotype of RF was IgM. More than $50 \%$ of patients had 2 or more RF isotypes. The majority of patients with positive RF had high levels of different isotypes, being the highest $\operatorname{lgM}$.

Disclosure of Interest: None declared

DOI: 10.1136/annrheumdis-2018-eular.6008

\section{AB1462-HPR ACTIVITY LIMITATIONS AND PERCEIVED HEALTH- RELATED QUALITY OF LIFE IN PEOPLE WITH INCLUSION BODY MYOSITIS - A CROSS-SECTIONAL STUDY}

M Regardt ${ }^{1,2}$, B. Eriksson ${ }^{1}$, L. Christopher-Stine ${ }^{3} .{ }^{1}$ Function Area Occupational therapy and Physioterapy, Karolinska University Hospital; ${ }^{2}$ Department of Learning, Informatics, Management and Ethics, Karolinska institutet, Stockholm, Sweden; ${ }^{3}$ Johns Hopkins Myositis Center, Baltimore, USA

Background: Inclusion body myositis (IBM) is a slowly progressive inflammatory myopathy with muscle weakness around thighs, knees and finger flexion muscles. Most people are 50 years or older at onset and there are more men than women with ratio of $2-3: 1$. The diagnosis leads to activity limitations in daily life.

Objectives: The aim of this study was to describe how individuals with IBM describe their activity limitation and how they estimate their perceived health-related quality of life as well as to describe the correlation between activity limitation and experienced health-related quality of life.

Methods: A quantitative cross-sectional study involving a total of 29 people with IBM participated. Data collection was performed in Stockholm Sweden. The Myositis Activities Profile (MAP) were used to measure activity limitation and the Short Form-36 (SF-36) were used to measure experienced health-related quality of life.
Results: Activity limitations were estimated from no difficulty to impossible to do. The activity with the highest value (very difficult) was movement. There was a significant difference between individuals with IBM and Swedish normative references measured with SF-36 in physical function, physical role function, general health and social function $(p \leq 0.01)$.

There were high correlations between SF-36 physical and social function with MAP's movement, household activities, social activity, work/school and leisure $\left(-0.872 \geq r_{s \leq} \leq 0.702 ; p \leq 0.001\right)$.

Conclusions: Participants estimated activity limitations in many areas, of which movement was estimated as very difficult. The study demonstrated correlation between activity limitations and the experience of impaired health-related quality of life. In order to make positive impact on the health-related quality of life, it is important to focus on social areas such as family, friends and leisure activities, as well as optimising everyday living with proper mobility tools.

Acknowledgements: We would like to thank all the participant for taking time to be part of this study.

We acknowledge The Myositis Association for making this study possible with a fellowship grant.

Disclosure of Interest: None declared

DOI: 10.1136/annrheumdis-2018-eular.6650

\section{AB1463-HPR IS THERE ANY DIFFERENCE IN JOINT POSITION SENSE AMONG DIFFERENT KNEE ANGLES IN PATIENTS WITH KNEE OSTEOARTHRITIS?}

M Eymir ${ }^{1}$, B. Ünver ${ }^{1}$, V. Karatosun ${ }^{2} .{ }^{1}$ School of Physical Therapy and Rehabilitation; ${ }^{2}$ Department of Orthopaedics and Traumatology, School of Medicine, Dokuz Eylul University, Izmir, Turkey

Background: The joint related structures such as joint capsule, menisci, ligaments, muscles, skin provide the sensory input for the knee proprioception. Individuals with knee osteoarthritis (OA) have poor proprioceptive sense when compared with the same ages healthy individuals. Due to $\mathrm{OA}$, the joint structures such as menisci, ligaments, and joint capsule rapidly undergo degeneration, and the deficiency of the knee proprioception progresses. Daily activities such as stair climbing, rise from a chair, walking require different knee joint angles. Therefore, the evaluation of the knee position sense at different joint angles is necessary for a better understanding of the knee proprioceptive sense deficit and for planning rehabilitation program in patients with knee OA.

Objectives: The purpose of this study was to analyse the knee joint position sense in different knee joint angles and to compare the results. Methods: The study group consisted of 80 patients (62 female/18 male, 124 knees), with unilateral or bilateral knee $\mathrm{OA}$ and with a mean age $65.5 \pm 9.1$ years were included in the study. Patients were evaluated regarding knee proprioception in knee joint angle $30^{\circ}, 60^{\circ}$ and $75^{\circ}$. The starting position was in knee joint angle $90^{\circ}$ flexion, and the target angles was attempted to replicate using active knee extension movements. Patients performed active joint angle replication test in sitting position at a standard back supported chair. The average of the 3 repetitions of active joint repositioning test was recorded position sense score. The angular displacements from the target angles (in knee joint angle $30^{\circ}$, $60^{\circ}, 75^{\circ}$ ) at the end of the active reproduction tests were recorded as position sense deficit scores.

Results: When the patients' knee position sense deficit at different joint angles (in knee joint angle $30^{\circ}, 60^{\circ}$ and $75^{\circ}$ ) were compared, there were statistically differences between at joint angle $75^{\circ}$ and $60^{\circ}$ $(p=0.002)$, and also there were statistically differences between at joint angle $75^{\circ}$ and $30^{\circ}(p=0.001)$. However, there were not statistically differences between the patients' knee position sense deficit at joint angle $30^{\circ}$ and $60^{\circ} \quad(p>0.05)$.

Conclusions: According to our results, the patients with knee $O A$ have better proprioceptive acuity at knee joint angle $30^{\circ}, 60^{\circ}$ than at knee joint angle $75^{\circ}$. Specifically, the detection of active knee movement occurred with lower target angle displacement at a starting knee angle close to terminal extension $\left(30^{\circ}\right)$ than at knee angles closer to midrange $\left(75^{\circ}\right)$. These results can be reasonably speculated that proprioceptive input arose primarily from hamstring muscle stretching, posterior capsule tautness, and possibly ligament strain. It could be argued that the observation of the greater motor responses at decreased angles likely have been facilitated from enhanced sensitivity of these sensory terminals. Also, the results of this study may provide guidance for future proprioceptive sensory evaluations and provide guidance for planning rehabilitation programs in patient with knee OA.

Disclosure of Interest: None declared

DOI: 10.1136/annrheumdis-2018-eular.5889 